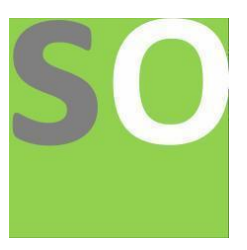

Article title: Dexamethasone is a gold weapon for immunomodulation in severe COVID-19 but has no effect on endocrine interleukin 6 and sex-linked response the problem - In silico study

Authors: Amr Kamel Khalil Ahmed[1], Mahmoud El Kazzaz [2]

Affiliations: Director of tuberculosis program Ghubera, public health department, First health cluster, Ministry of health, Riyadh, Saudia Arabia[1], Department of chemistry and biochemistry, Faculty of Science, Damietta University, Egypt[2]

Orcid ids: 0000-0003-3477-236X[1], 0000-0003-3703-520X[2]

Contact e-mail: drmedahmed@gmail.com

License information: This work has been published open access under Creative Commons Attribution License http://creativecommons.org/licenses/by/4.0/, which permits unrestricted use, distribution, and reproduction in any medium, provided the original work is properly cited. Conditions, terms of use and publishing policy can be found at https://www.scienceopen.com/.

Preprint statement: This article is a preprint and has not been peer-reviewed, under consideration and submitted to ScienceOpen Preprints for open peer review.

Funder: NO

DOI: 10.14293/S2199-1006.1.SOR-.PPO5NHG.v1

Preprint first posted online: 02 December 2021

Keywords: dexamethasone, ACTH, endocrine, interleukin 6, covid-19, cortisol, adrenal gland 


\title{
Dexamethasone is a gold weapon for immunomodulation in severe COVID-19 but has no effect on endocrine interleukin 6 and sex- linked response the problem - In silico study
}

\author{
Amr Kamel khalil Ahmed (drmedahmed@gmail.com) Director of tuberculosis \\ program Ghubera, public health department, First health cluster, Ministry of \\ health, Riyadh, Saudia Arabia https://orcid.org/0000-0003-3477-236X \\ Mahmoud El Kazzaz (mahmoudramadan2051@yahoo.com) Department of \\ chemistry and biochemistry, Faculty of Science, Damietta University, Egypt \\ https://orcid.org/0000-0003-3703-520X
}

\begin{abstract}
:
Until now after nearly two years from lethally pandemic of covid-19 which is considered a joker virus as bypass many immune defenses in our bodies like innate and adaptive immunity with all types of cells but there are important markers at the long road for treatment like Interleukin (Il-6), neutrophils, high ferritin, high D dimer. Also, post-covid or long covid effects like neuropsychiatric problems like smell dysfunctions and hormonal dysfunctions. Therefore, this article will give a spotlight on the adrenal gland as a place where the immune and endocrine systems meet. Additionally, dexamethasone has no effect on Il-6 secreted from adrenal cortex and this allows Il-6 to be produced during stress. We need a new classification IL-6 at physiological and pathological aspects as the stimulatory factors are different. Endocrine Il- 6 is stimulated by ACTH but the immune Il- 6 is stimulated by il-1 $\beta$ and angiotensin II. Of note, dexamethasone saves critically covid-19 patients but in the same time has no affection on Il-6 of endocrine origin either basal or stimulated. Therefore, adrenal gland serves as a vital link between the endocrine and immunological systems at the pathogenesis of covid-19. Besides, Il-6 is the key sexlinked variation at their immune responses.
\end{abstract}

\section{Main body}

It is well recognized that the hypothalamic corticotropin-releasing hormone $(\mathrm{CRH})$ is responsible for pituitary activation and the release of adrenocorticotropic hormone $(\mathrm{ACTH})$, which stimulates the adrenal cortex secreting glucocorticoids (GCs). 
Interleukin-6 (IL-6) is generated by the adrenal gland zona glomerulosa cells and this is controlled by IL-1 $\alpha$, IL-1 $\beta$, ACTH, and angiotensin II. Synthetic glucocorticoid dexamethasone is particularly effective toward immune organs like the spleen and all immunological tissues. Dexamethasone is regarded as an IL-6 inhibitor in various tissues. However, it showed no effect on IL-6 produced in the adrenal gland. ACTH is a conventional endocrine hormone and the combined effect of IL-1 $\beta$ and ACTH can release much more IL-6 than the individual effect of each one alone [1].

Of note, IL-6 generated by cells of zona glomerulosa can be passed to the zona fasciculata and zona reticularis through adrenal blood supplies that connect these regions. The physiological responses of the hypothalamic-pituitary-adrenal (HTPA) axis may be also influenced by the adrenal IL-6. Previous studies demonstrated that IL-1 and IL-6 stimulated ACTH production and secretion, and ACTH can stimulate IL-6 secretion in rat zona glomerulosa cells. ACTH and angiotensin II had no influence on IL-6 secrete by zona fasciculata or reticularis [1, 2].

Both in animal models and humans, estrogens improve humoral immunity while decrease cellular responses, whereas androgens inhibit mechanisms. In addition, females are more usually seriously impacted by autoimmune diseases. The same study found that males produced considerably more ACTH than females. Also, intravenous infusions of ACTH and cortisol stimulate IL-6 secretion in healthy young people [3]. Interestingly, both at the start of the study and after IL-6 stimulating dose, females had considerably greater cortisol/ACTH ratios than men. These findings imply that the generation of GCs in males and females requires comparable amounts of IL-6. They do, however, show that male and female adrenals have distinct sensitivity to ACTH and perhaps to direct IL-6 activation. Overall, in men but not in women, peak cortisol levels were substantially connected to circulating 11-6 levels, but the relationship between ACTH and cortisol levels was inverted. In addition, females had significantly higher cortisol/ACTH ratios than males, suggesting that high estradiol levels after menopause or post-menopause keep cortisol levels high in relation to plasma levels of ACTH [3]. In addition, testosterone reduces the rat's HTPA axis response to IL-6. This suggests that, in the presence of gonadal steroids, other mechanisms, in addition to the regulation of IL-6 release, are involved in limiting the 
HTPA inflammatory response [4]. In severe COVID-19 patients, dexamethasone altered neutrophils, changed IFN ${ }^{\text {active }}$ neutrophils, suppressed interferon-stimulated genes, and activated IL-1R2+ve neutrophils. Dexamethasone also increased the number of immunosuppressive immature neutrophils and changed cellular connections by switching neutrophils from information receivers to producers.

Male COVID-19 patients exhibited a larger proportion of IFN ${ }^{\text {active }}$ neutrophils than female ones, and favoured steroid-induced immature neutrophil development, which might affect outcomes. "Specifically in men, we detect an increased neutrophil interferon response that is greatly inhibited when a patient is given dexamethasone," Biernaskie said. Females, on the other hand, "had a considerably more tempered neutrophil interferon response, therefore dexamethasone had less impact." Dexamethasone showed different effects according to sex, which could have serious consequences for sex-dependent outcomes and treatment efficacy in severe COVID19 symptoms [5].

The nuclear factor kappa B (NF-kB) is the principal modulator of IL-6, and the first research established Steroids' suppression of NF-kB in the cells of early newborn with breathing difficulties by Aghai et al. This study further demonstrates that dexamethasone's anti-inflammatory impact in preterm newborns may be mediated by NF-kB, which is important for controlling the key inflammatory mediators linked to acute lung injury. Steroids' anti-inflammatory impact via suppression of proinflammatory cytokines may be achieved by inhibition of the transcription factor NFB [6]. Human respiratory smooth muscle IL-6 production triggered by bradykinin via B2 receptors is responsive to corticosteroids and controlled by cytokines secreted by t-helper cells.

Dexamethasone inhibited NF-kB-induced IL-6 production nearly entirely, lowering it by more than $95 \%$. Because dexamethasone was somewhat successful at reducing IL6 production in response to TNF- $\alpha$, the inhibitory impact of dexamethasone on IL-6 transcription appears to be sensory, implying that cytokine receptors and GPCRs may control IL-6 gene expression via separate subsequent processes. In airway smooth muscle (ASM) cells, dexamethasone totally inhibited BK-induced IL-8 expression. Dexamethasone reduces BK's capacity to create prostaglandin E2 (PGE2), a crucial route in the control of IL-6 production in ASM cells, which may reduce IL-6 
expression. Anti-inflammatory effects of dexamethasone as well as steroids are mediated in part by interactions with transcriptional regulators such as NF-kB and activator protein 1 (AP-1) [7].

Research published in the journal Nature found that dexamethasone halted nearly a third of deaths in severe COVID-19 patients. The steroid, however, showed little impact on patients with moderate instances of COVID-19. The authors hypothesise that the anti-inflammatory response of dexamethasone may be connected to its therapeutic impact on severely sick COVID-19 patients. However, the vast majority of serious cases suffered from critical illness-related corticosteroid insufficiency (CIRCI), and dexamethasone's therapeutic effect may be due to its increase of cortical function [8].

\section{Table 1}

\begin{tabular}{|c|c|c|c|}
\hline Immune il-6 & Endocrine il-6 & $\begin{array}{l}\text { Type I adrenal } \\
\text { steroid receptors }\end{array}$ & $\begin{array}{l}\text { Type II adrenal steroid } \\
\text { receptors }\end{array}$ \\
\hline $\begin{array}{l}\text { Il-1 beta il-1 } \\
\text { alfa } \\
\text { angotensibn II }\end{array}$ & $\begin{array}{l}\text { ACTH } \\
\text { stimulated }\end{array}$ & $\begin{array}{l}\text { Mineralocorticoid } \\
\text { receptors }\end{array}$ & Glucocorticoid receptors \\
\hline $\begin{array}{l}\text { Dexamethasone } \\
\text { effect }\end{array}$ & $\begin{array}{l}\text { No } \\
\text { dexamethasone } \\
\text { effect }\end{array}$ & $\begin{array}{l}\text { High affinity for } \\
\text { endogenous cortisol }\end{array}$ & $\begin{array}{l}\text { High affinity to synthetic } \\
\text { glucocorticoids } \\
\text { dexamethasone }\end{array}$ \\
\hline $\begin{array}{l}\text { Zona } \\
\text { glomerlousa }\end{array}$ & $\begin{array}{l}\text { Zona } \\
\text { glomerluosa }\end{array}$ & $\begin{array}{lr}\text { Aldosterone } & \text { agonists } \\
\text { significantly decrease } \\
\text { levels of } & \text { plasma } \\
\text { neutrophils } & \text { and } \\
\text { natural killer } & (\mathrm{NK}) \\
\text { cells } & \end{array}$ & $\begin{array}{l}\text { Significant increase in } \\
\text { neutrophils and natural } \\
\text { killer cells after } \\
\text { administration of type ii } \\
\text { receptors } \\
\text { RU28362 }\end{array}$ \\
\hline
\end{tabular}

Since dexamethasone does not bind to corticosterone-binding globulin (CBG), it can reach all immune systems equally, relinquishing the exact properties provided by endogenous hormones. Adrenaline hormones can affect both cellular proliferation and maturation in the bone marrow, particularly $\mathrm{T}$ cells in the thymus. Adrenaline hormones have been proven to alter the ratio of macrophage to granulocyte progenitors by reducing macrophage colony formation by $75 \%$ to $90 \%$ while increasing granulocyte colony formation by $50 \%$ to $100 \%$. Cortisol has also been shown to prevent PMA-induced monocyte-to-macrophage development in the human monocytic cell line U-937. The potential of adrenal hormones to promote 
programmed cell death, also known as apoptosis, is one of the most dramatic elements of their effect on immune cells. Treatment with glucocorticoids lowered blood levels of eosinophils and basophils, which is assumed to be connected to cell redistribution from the blood to the spleen and other compartments. Surprisingly, glucocorticoids boost neutrophil counts while reducing while simultaneously decreasing the amount of circulating immune cells [9]. Adrenaline hormones are hypothesized to promote blood neutrophil levels by increasing neutrophil exit from bone marrow, delaying neutrophil outflow from circulation, and lengthening the half-life of circulating neutrophils. After one session of confinement, minor yet severe stress, macrocytopenia and leukopenia, as well as macroneutropenia, were observed in the peripheral blood of rats [9].

It has been discovered that diurnal fluctuations in circulating lymphocytes occur in healthy people but not in individuals with adrenal insufficiency. These data also imply that cortisol administration decrease lymphocytic counts in a dose-dependent manner. In addition, prior research found that adrenalectomy eliminates the diurnal regularity in lymphocyte counts and that a single dosage of prednisolone caused a reversible drop in lymphocytic counts immediately after medication delivery. Aside from their effect on normal leukocyte dispersion [9].

In the absence of infection or inflammation, GCs prevent neutrophil, eosinophil, and monocyte-macrophage entry into inflammatory areas. This is regarded as a significant way in the reduction of inflammation caused by glucocorticoids. Adrenal hormones have been shown to alter cytokine receptor expression as well as cytokine production. The synthesis of the IL-2 receptor $a$ and $b$ chains has been demonstrated to be suppressed by GCs at both the transcriptional and posttranscriptional stages. The fact that glucocorticoids inhibit IL-2-driven lymphocyte proliferation adds to this [9]

It has been shown that glucocorticoids increase the amount of IL-1 and IL-6 receptors. Another kind of acute immunopathology may emerge as a result of increased cytokine production during infections. This route was revealed in gram-negative bacterial sepsis septic shock. Lipopolysaccharide (LPS), a bacterial endotoxin, activates mononuclear phagocytes under these circumstances, resulting in extremely high cytokine production. 
TNF- $\alpha$, IL-1, and IL- 6 cytokine cascades are activated. TNF- $\alpha$ production promotes the production of IL-1 and IL-6. IL-12 and interferon-g (IFN-g) are expressed too early in the cytokine storm [9].

Septic shock syndrome is a life-threatening condition marked by circulatory collapse and leakage, in addition to intravascular coagulation. Interactions between $\mathrm{T}$ cells can lead to the generation of harmful cytokines. Bacterial superantigens induce abnormally high levels of $\mathrm{T}$ lymphocytes in naive hosts, possibly contributing to the septicemia linked with some infections caused by gram $^{+v e}$ bacterial. Additionally, higher cytokines produced by T-helpers have been associated to pathology of hemorrhagic disease caused by the dengue virus (Dangue fever) and recurrent dengue virus infections' lung immunopathology. These are some of the scenarios in which a "overactive" immune response might cause illness [9]. 


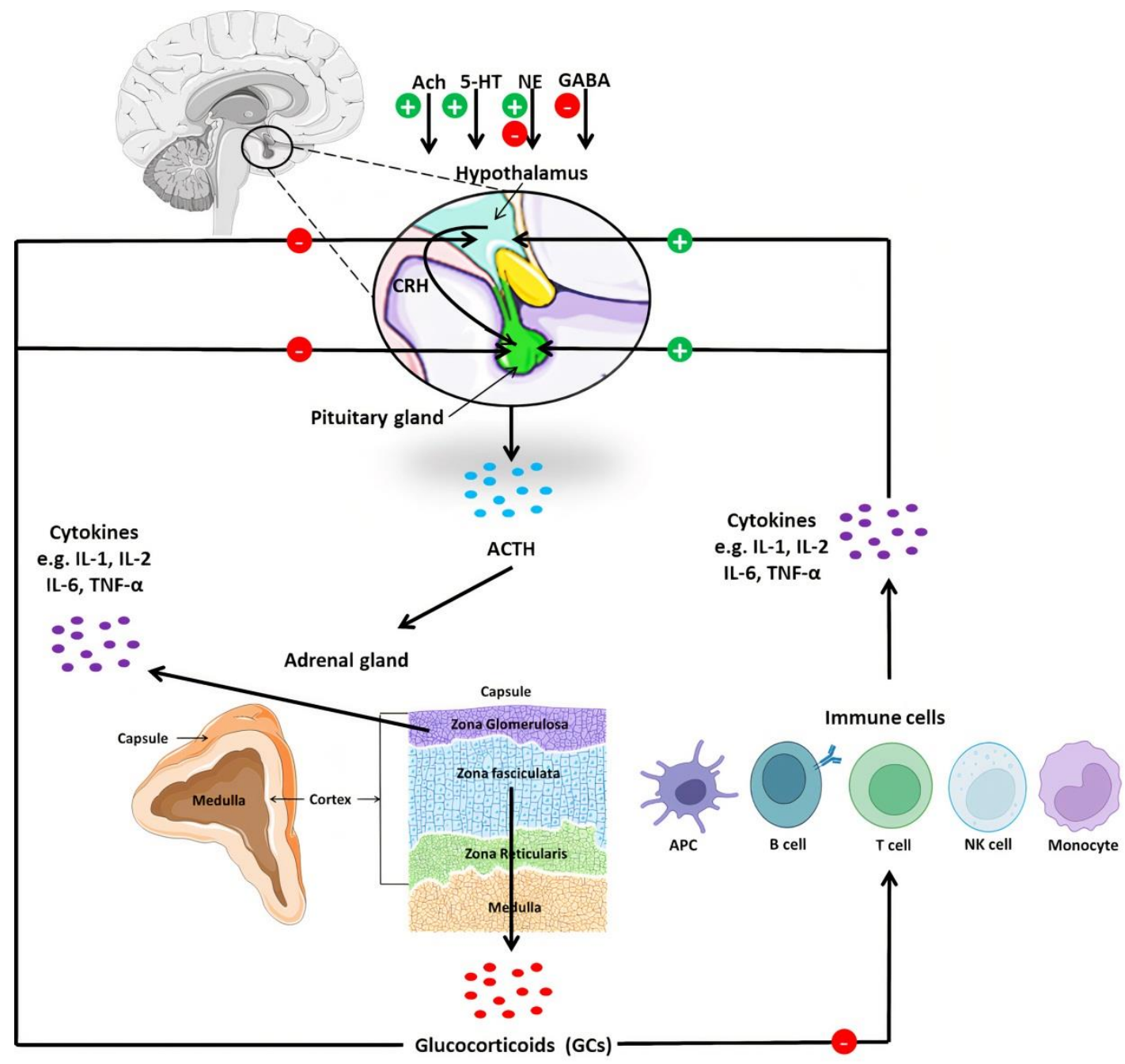

Figure 1. Schematic illustration of the hypothalamic-pituitary-adrenal axis (HTPA axis) and the immunomodulation pathway. Corticotropin-releasing hormone $(\mathrm{CRH})$ from the hypothalamus is responsible for pituitary activation and releasing of adrenocorticotropic hormone $(\mathrm{ACTH})$ which stimulate the adrenal cortex to secrete glucocorticoids (GCs). GCs (or dexamethasone as a synthetic example) have a critical role in immune suppression by blocking the secretion of proinflammatory cytokines (especially IL-6) secreted by immune cells. On the other hand, dexamethasone suppresses production of IL-6 in many different tissues, however, it has no impact on IL-6 produced in the adrenal cortex [1]. NE, Norepinephrine; GABA, gamma-Aminobutyric acid; 5-HT, 5-hydroxytryptamine; Ach, AcetylCholine; IL, Interleukins; TNF- $\alpha$, Tumor necrosis factor.

\section{In silico molecular docking of dexamethasone with IL-6}

Using AutoDock Vina, the molecule Dexamethasone was docked with the receptor Interleukin-6 and analyzed for binding energy and protein-ligand interactions. The binding affinity was found $-6.7 \mathrm{Kcal} / \mathrm{mol}$. Pymol was used to create complex receptor and ligand file, while Discovery Studio was used to find interactions, respectively. 


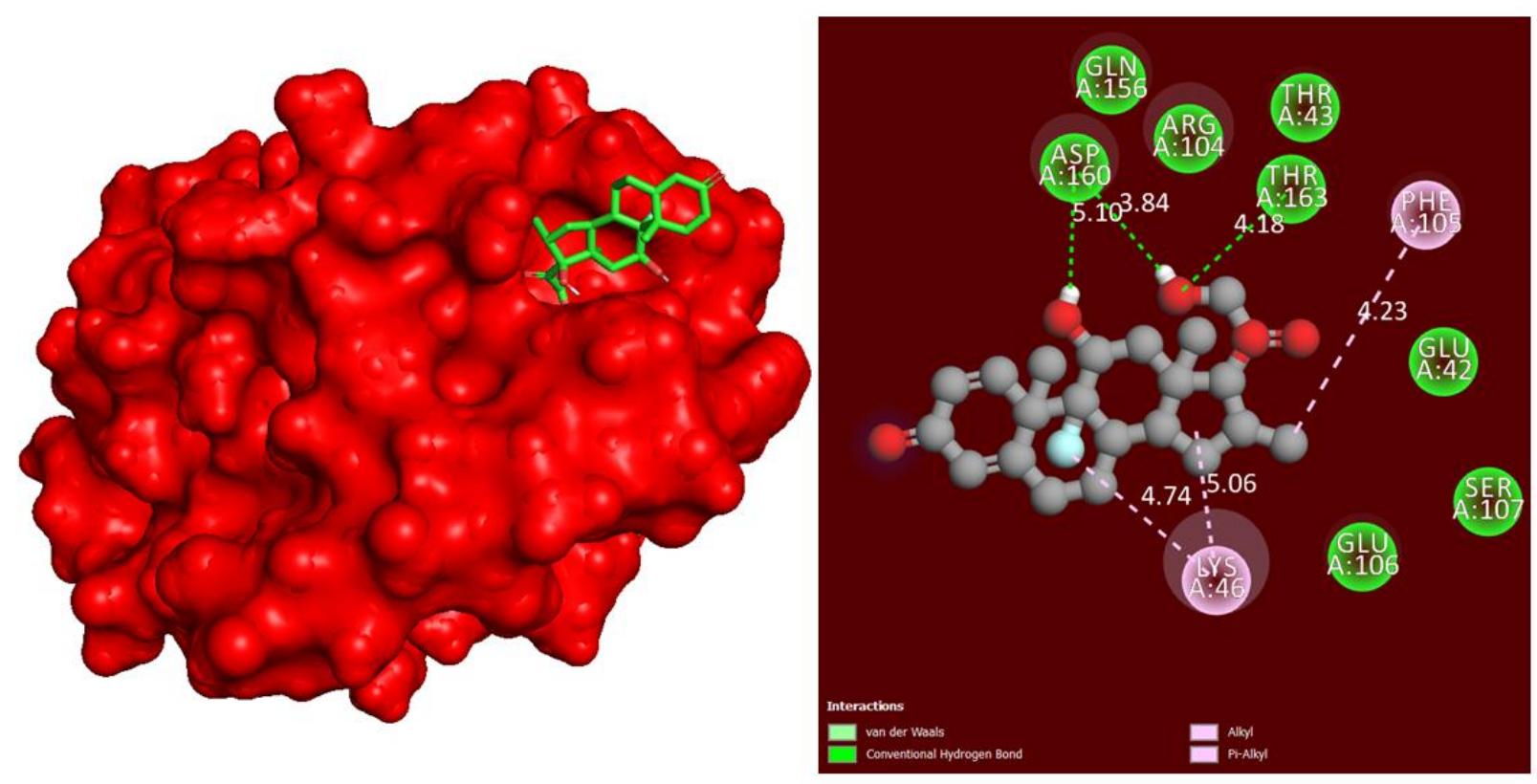

Figure 2 Binding interaction of Dexamethasone with Interleukin-6. It shows binding pocket of protein in 3D and 2D. Important binding residues making different kind of interaction present in binding site are shown in 2D image.

$\begin{array}{ll}\text { Abbreviations } & \\ \text { ACTH } & \text { adrenocorticotropic hormone } \\ \text { AP-1 } & \text { activator protein 1 } \\ \text { ASM } & \text { airway smooth muscle } \\ \text { CBG } & \text { corticosterone binding globulin } \\ \text { CIRCI } & \text { critical illness-related corticosteroid insufficiency } \\ \text { CRH } & \text { corticotropin-releasing hormone } \\ \text { GCs } & \text { glucocorticoids } \\ \text { HPA } & \text { hypothalamic-pituitary-adrenal } \\ \text { HTPA } & \text { hypothalamic-pituitary-adrenal } \\ \text { IFN-g } & \text { interferon-g } \\ \text { IL } & \text { Interleukin } \\ \text { LPS } & \text { lipopolysaccharide } \\ \text { PGE2 } & \text { prostaglandin E2 }\end{array}$




\section{References:}

1. Judd AM, MacLeod RM (1992) Adrenocorticotropin increases interleukin-6 release from rat adrenal zona glomerulosa cells. Endocrinology 130:12451254. https://doi.org/10.1210/endo.130.3.1311232

2. Jones TH (1994) Interleukin-6 an endocrine cytokine. Clin Endocrinol (Oxf) 40:703-713. https://doi.org/10.1111/j.1365-2265.1994.tb02502.x

3. Silva C, Ines LS, Nour D, et al (2002) Differential male and female adrenal cortical steroid hormone and cortisol responses to interleukin-6 in humans. Ann N Y Acad Sci 966:68-72. https://doi.org/10.1111/j.17496632.2002.tb04203.x

4. Papadopoulos AD, Wardlaw SL (2000) Testosterone suppresses the response of the hypothalamic-pituitary-adrenal axis to interleukin-6. Neuroimmunomodulation 8:39-44. https://doi.org/10.1159/000026451

5. Sinha S, Rosin NL, Arora R, et al (2021) Dexamethasone modulates immature neutrophils and interferon programming in severe COVID-19. Nat Med. https://doi.org/10.1038/s41591-021-01576-3

6. Aghai ZH, Kumar S, Farhath S, et al (2006) Dexamethasone suppresses expression of Nuclear Factor-kappaB in the cells of tracheobronchial lavage fluid in premature neonates with respiratory distress. Pediatr Res 59:811-815. https://doi.org/10.1203/01.pdr.0000219120.92049.b3

7. Huang C-D, Tliba O, Panettieri RAJ, Amrani Y (2003) Bradykinin induces interleukin-6 production in human airway smooth muscle cells: modulation by Th2 cytokines and dexamethasone. Am J Respir Cell Mol Biol 28:330-338. https://doi.org/10.1165/rcmb.2002-0040OC

8. Mao Y, Xu B, Guan W, et al (2020) The Adrenal Cortex, an Underestimated Site of SARS-CoV-2 Infection. Front Endocrinol (Lausanne) 11:593179. https://doi.org/10.3389/fendo.2020.593179

9. McEwen BS, Biron CA, Brunson KW, et al (1997) The role of adrenocorticoids as modulators of immune function in health and disease: neural, endocrine and immune interactions. Brain Res Brain Res Rev 23:79133. https://doi.org/10.1016/s0165-0173(96)00012-4 